\title{
Early stages of sex chromosome differentiation in fish as analysed by simple repetitive DNA sequences *
}

\author{
Indrajit Nanda ${ }^{1}$, Manfred Schartl ${ }^{2}$, Wolfgang Feichtinger ${ }^{1}$, Jörg T. Epplen ${ }^{3}$, and Michael Schmid ${ }^{1}$ \\ ${ }^{1}$ Institut für Humangenetik der Universität, Am Hubland, W-8700 Würzburg, Federal Republic of Germany \\ 2 Gene Center, and ${ }^{3}$ Max-Planck-Institut für Psychiatrie, Am Klopferspitz 18a, W-8033 Martinsried, Federal Republic of Germany
}

Received February 6, 1991 / in revised form May 17, 1991

Accepted May 17, 1991 by E.R. Schmidt

\begin{abstract}
Animal sex chromosome evolution has started on different occasions with a homologous pair of autosomes leading to morphologically differentiated gonosomes. In contrast to other vertebrate classes, among fishes cytologically demonstrable sex chromosomes are rare. In reptiles, certain motifs of simple tandemly repeated DNA sequences like (gata) $)_{\mathbf{n}} /(\text { gaca })_{m}$ are associated with the constitutive heterochromatin of sex chromosomes. In this study a panel of simple repetitive sequence probes was hybridized to restriction enzyme digested genomic DNA of poeciliid fishes. Apparent male heterogamety previously established by genetic experiments in Poecilia reticulata (guppy) was correlated with male-specific hybridization using the $(\mathrm{GACA})_{4}$ probe. The (GATA $)_{4}$ oligonucleotide identifies certain male guppies by a Y chromosomal polymorphism in the outbred population. In contrast none of the genetically defined heterogametic situations in Xiphophorus could be verified consistently using the collection of simple repetitive sequence probes. Only individuals from particular populations produced sex-specific patterns of hybridization with (GATA) 4 . Additional poeciliid species (P. sphenops, $P$. velifera) harbour different sex-specifically organized simple repeat motifs. The observed sex-specific hybridization patterns were substantiated by banding analyses of the karyotypes and by in situ hybridization using the $(\mathrm{GACA})_{4}$ probe.
\end{abstract}

\section{Introduction}

The class of teleost fish exhibits diverse forms of sexuality, ranging from simultaneous or successive hermaphroditism to gonochorism with early or late sexual differentiation (Price 1984). Using cytological techniques it has been demonstrated in several species that both the

* Dedicated to Professor Karl Sperling on the occasion of his 50th birthday

Offprint requests to: $\mathrm{M}$. Schmid
$\mathrm{XY} \delta / \mathrm{XX}$ ind the $\mathrm{ZW}+\mathrm{ZZ}$ to mechanisms of chromosomal sex determination occur. All sex chromosomes in fish identified cytologically to date are distinctively heteromorphic in one sex and thus can be recognized by simple conventional staining methods (Ebeling and Chen 1970; Gold 1979; Beçak 1983). Yet simple karyological analyses have failed to detect heterogametic sex chromosomes in many gonochoristic fishes displaying conspiucuous sexual dimorphism. But even in the absence of size differences between gonosomes, sex determination in many teleost species can be explained by means of a chromosomal mechanism. This has been demonstrated by genetic studies on species with sexlinked colour genes (Aida 1921; Winge and Ditlevsen 1947) and breeding experiments with sex-reversed animals (Yamamoto 1961). Obviously these sex determining chromosomes are still in an initial stage of differentiation and their genetic material has not diverged considerably.

Among teleosts, the sex determination of viviparous fish of the subgenus Poecilia has been extensively studied. The existence of heterogamety has been suggested from studies of colour gene inheritance and other sexlinked markers in the guppy (Poecilia reticulata; Winge 1922) and in several species of Xiphophorus (Platypoecilus) (Gordon 1947, 1951; Kallman 1984). However, convincing evidence for cytological heterogamety is lacking (but see Foerster and Anders 1977). The present experimental approach to study the mechanism(s) underlying the differentiation of sex chromosomes utilizes sex-specifically organized DNA sequences. Singh et al. (1981) have described sex-specific satellite DNAs from snakes that hybridize preferentially to the $\mathrm{W}$ chromosome in the heterogametic females. The Banded $k$ rait minor satellite $(B \mathrm{~km})$ sequences are present in the heterogametic sex of many vertebrates, e.g. on the $\mathrm{W}$ chromosome of birds (Jones and Singh 1985) and the Y chromosome of the mouse (Epplen et al. 1982; Singh et al. 1984). A considerable part of this satellite sequence consists of particular simple repetitive sequences, (gata) ${ }_{n}$ and (ga$\mathrm{ca})_{\mathrm{m}}$, which are present in a wide range of vertebrates (Epplen 1988). These simple repeats have allowed the 
detection of molecular and structural differences even between apparently homomorphic sex chromosomes in the guppy (Nanda et al. 1990). Here we present studies on Xiphophorus and Poecilia species undertaken in order (1) to analyse the association of simple repetitive sequences with the genetically apparent heterogamety and (2) to confirm the presence of simple repetitive sequences like (gata) and (gaca) $)_{m}$ in the early evolution of the heterogametic condition.

The platyfish Xiphophorus maculatus represents the most extensively studied system involving natural populations where precise genetic homology between the sex chromosomes could be derived. In natural populations there are three types of chromosomal constitution in females, WY, WX and XX, and two types in males, $X Y$ and YY (Kallman 1973, 1984). Although the sex chromosomes in this species have not been identified convincingly (but see Foerster and Anders 1977), the constant sex ratios in broods from individuals with characteristic sex-linked markers attest the existence of three types of sex chromosomes. While $X$. maculatus sex chromosomes are homologous with the sex chromosomes of several other species of Xiphophorus, there are also instances of atypical sex determination in $X$. maculatus where phenotypic sex does not concur with chromosomal sex (Kallman 1984). In other species of these genera sex determination has been found to conform with other chromosomal mechanisms with the extreme case of a population of $X$. helleri in which a polyfactorial mode was reported (Peters 1964). In view of the extreme form of heterogamety in $X$. maculatus we examine here the association of (gata) $)_{n}$ and (gaca) $)_{m}$ sequences in cytologically undefined sex chromosomes of poeciliid fishes.

\section{Materials and methods}

Mature male and female specimens of ornamental strains of $P$. reticulata (guppy), black molly ( $P$. shenops, var. melanistica; the entirely black breed is known as the melanistica variant) and sailfin molly $(P$. velifera) were purchased from local animal dealers.

Fish from two populations of $X$. helleri were used. The Rio Lancetilla stock shows differing sex ratios and male size dimorphism in many broods. The differing sex ratios have been attributed to polyfactorial sex determination (Peters 1964). The population of the Laguna Catemaco has an overall sex ratio of $1: 1$ and no size dimorphism of males was observed in our stock. Specimens of $X$. maculatus were from populations of the Rio Papaloapan system, the Rio Coatzecoalcos system and the Rio Jamapa.

Founder fish for the stocks were obtained from A. and F. Anders (Gießen, FRG), K.D. Kallman (New York, USA) or during a collection trip to Mexico in spring 1989, respectively. All experimental fish were maintained under standard conditions (Kallman 1973). The Xiphophorus strains were bred in closed stocks derived from at least two to three brother-sister matings to minimize polymorphism of the sex chromosomes analysed.

Chromosome preparation, banding and in situ hybridization. The techniques used for the preparation of mitotic chromosomes, demonstration of constitutive heterochromatin and in situ hybridization using the biotinylated (GACA) ${ }_{4}$ oligonucleotide have been described previously (Haaf and Schmid 1984; Nanda et al. 1990).

DNA preparation and oligonucleotide hybridization. Genomic DNA was isolated from brain, liver, spleen and gill according to Blin and Stafford (1976). DNA (5 $\mu \mathrm{g})$ from all individuals was digested with restriction endonucleases (HaeIII, HinfI, AluI, Sau3AI) according to the recommendations of the supplier (BoehringerMannheim, FRG) and resolved on $0.8 \%$ horizontal agarose gels in TAE buffer $(40 \mathrm{mM}$ Tris, $12 \mathrm{mM}$ sodium acetate, $2 \mathrm{mM}$ EDTA, $\mathrm{pH} 8.3)$ at $2 \mathrm{~V} / \mathrm{cm}$ for about $40 \mathrm{~h}$. Prior to hybridization the gels were dry-blotted, stained with ethidium bromide, photographed, denatured, neutralized and reequilibrated as described (Schäfer et al. 1988). The oligonucleotide probes specific for simple repeats were synthesized on an automated DNA synthesizer (Applied Biosystems 381A, Weiterstadt, FRG) and were end-labelled with [ $\gamma^{32}$ P]ATP (Amersham, Braunschweig, FRG) in a standard kinase reaction. Hybridizations were carried out for $3-4 \mathrm{~h}$ at $35^{\circ} \mathrm{C}$ for $(\mathrm{GATA})_{4}$, at $43^{\circ} \mathrm{C}$ for $(\mathrm{GACA})_{4},(\mathrm{CA})_{8}$ and $(\mathrm{GGAT})_{4}$, and at $45^{\circ} \mathrm{C}$ for $(\mathrm{CAC})_{5}$ in $5 \times$ SSPE $(20 \times$ SSPE is $3 \mathrm{M} \mathrm{NaCl}, 200 \mathrm{mM}$ $\mathrm{NaH}_{2} \mathrm{PO}_{4} \times \mathrm{H}_{2} \mathrm{O}, 20 \mathrm{mM}$ EDTA), $0.1 \%$ sodium dodecyl sulphate (SDS), $10 \mu \mathrm{g} / \mathrm{ml}$ sonicated and denatured Escherichia coli DNA and $1 \times 10^{6} \mathrm{cpm} / \mathrm{ml}$ of the labelled probes. After hybridization gels were washed three times for $30 \mathrm{~min}$ each at room temperature in $6 \times \mathrm{SSC}(0.9 \mathrm{M} \mathrm{NaCl}, 90 \mathrm{mM}$ trisodium citrate) followed by a $1 \mathrm{~min}$ wash at the hybridization temperature. Gels were then exposed to Kodak XAR-5 film at room temperature. Before reprobing, the gels were washed twice for $30 \mathrm{~min}$ each in $5 \mathrm{mM}$ EDTA at $60^{\circ} \mathrm{C}$ and finally reequilibrated in $6 \times \mathrm{SSC}$.

\section{Results}

\section{Sex-specific hybridization with simple repeat probes}

Sex-specific hybridization using simple repeat probes was investigated in at least five guppies of both sexes (juvenile individuals were avoided whereever possible). HinfI- and/or AluI-digested genomic DNA samples from outbred male and female guppies were hybridized with the $(\mathrm{GATA})_{4}$ and (GACA) 4 probes. In contrast to females, males displayed a single prominent (GACA) ${ }_{4}$ band in the high molecular weight range $(>23 \mathrm{~kb}$; see Fig. 1).

The (GATA $)_{4}$ probe reveals a Y chromosomal polymorphism (Fig. 1, band around $23 \mathrm{~kb}$; f approx. 0.30.4). Using mixed oligonucleotide probes consisting of varying amounts of (gata $)_{n}$ and (gaca $)_{m}$ sequences $[(G A-$ $\mathrm{TA})_{3}(\mathrm{GACA})_{2}$ and (GATA) ${ }_{2}$ GACA(GATA) ${ }_{2}$ ], we hybridized genomic DNA from the individuals that were displaying male-specific signals with the (GATA) probe. In all combinations of simple $(\text { gata })_{n} /(\text { gaca })_{m}$ repeats (mixed oligonucleotide probes) sex specificity similar to that found with $(\mathrm{GACA})_{4}$ was observed (data not shown). Thus the polymorphism in the organization of the simple sequences from the guppy $\mathrm{Y}$ chromosome could be demonstrated only with the pure synthetic $(\mathrm{GATA})_{4}$ probe.

The genomes of $P$. sphenops and $P$. velifera exhibit comparatively low amounts of (gata $)_{n}$ and (gaca) $)_{m}$ simple sequences. In contrast to the guppy, in $P$. sphenops the longest prominent (GACA) $)_{4}$ band appeared at around $6.6 \mathrm{~kb}$. However, upon over-exposing autoradiographs it is possible to obtain faint hybridization at the high molecular weight range only in females (Figs. 1, 2). In $P$. velifera both (gata) $)_{n}$ and (gaca) $)_{m}$ sequences are even less abundant. After long exposure faint signals were observed with (GACA) $)_{4}$ in the $23 \mathrm{~kb}$ region in both sexes (data not shown). Interestingly there was promi- 


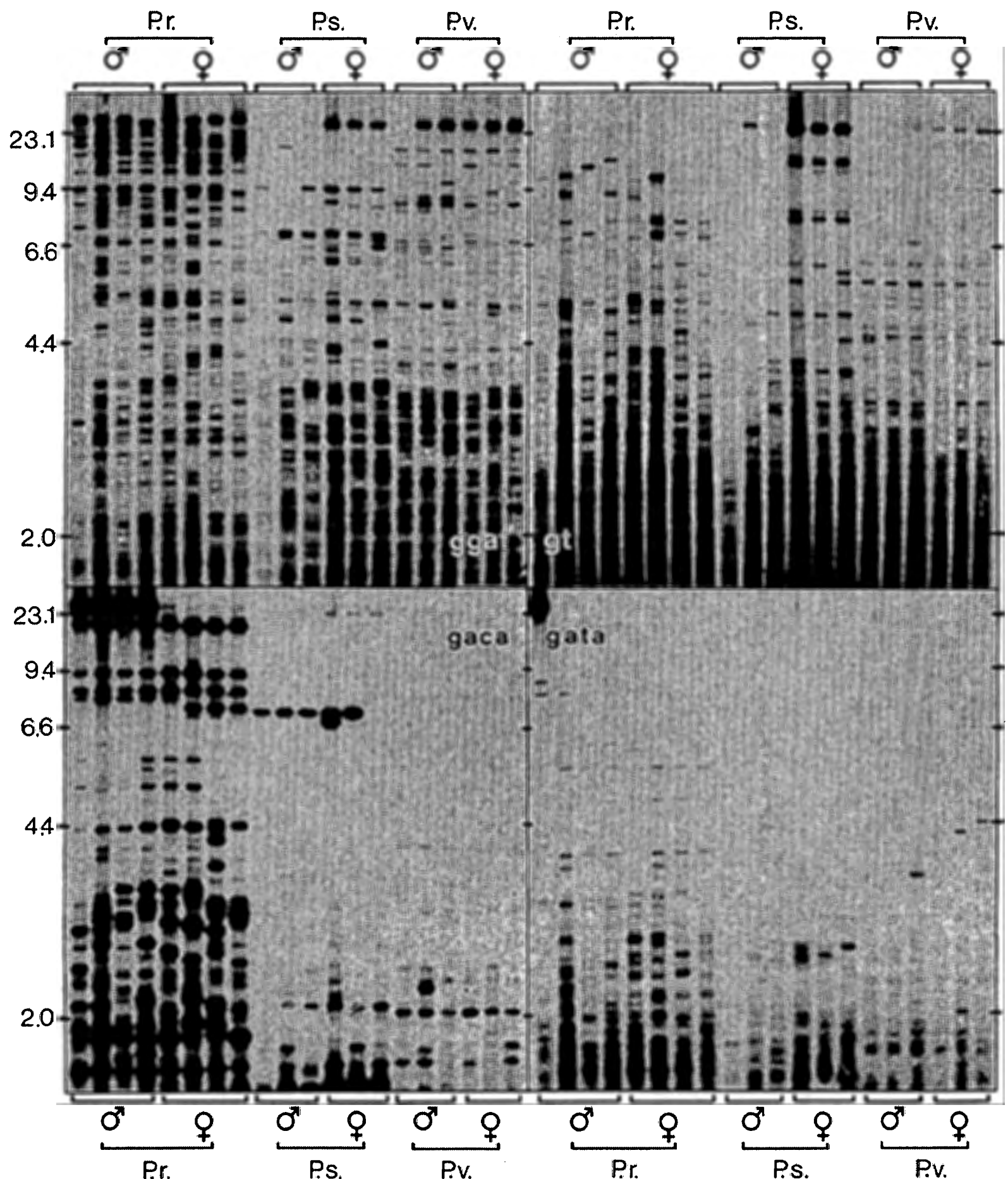

Fig. 1. In-gel hybridization of genomic DNA from Poecilia reticulata (P.r.), P. sphenops (P.s.) and P. velifera (P.v.) with the simple repetitive oligonucleotide probes $(G G A T)_{4},(G T)_{8},(G A C A)_{4}$ and $(G A T A)_{4}$. DNA was prepared from three or four male and female individuals and separated by agarose gel electrophoresis after HinfI digestion. The gel was dried and hybridized consecutively with

the probes. Note the following pronounced male/female differences: (1) P.s. using (GGAT) in the $>23 \mathrm{~kb}$ range; (2) P.v. using $(G T)_{8}$ at approx. 23, 20 and $10 \mathrm{~kb}$; (3) P.r. $>23 \mathrm{~kb}$ using $(G A C A)_{4}$. The prominent signal obtained with $(G A T A)_{4}$ in one male guppy (on the left-hand side) is due to a Y chromosomal polymorphism. Length markers are indicated in kilobases 


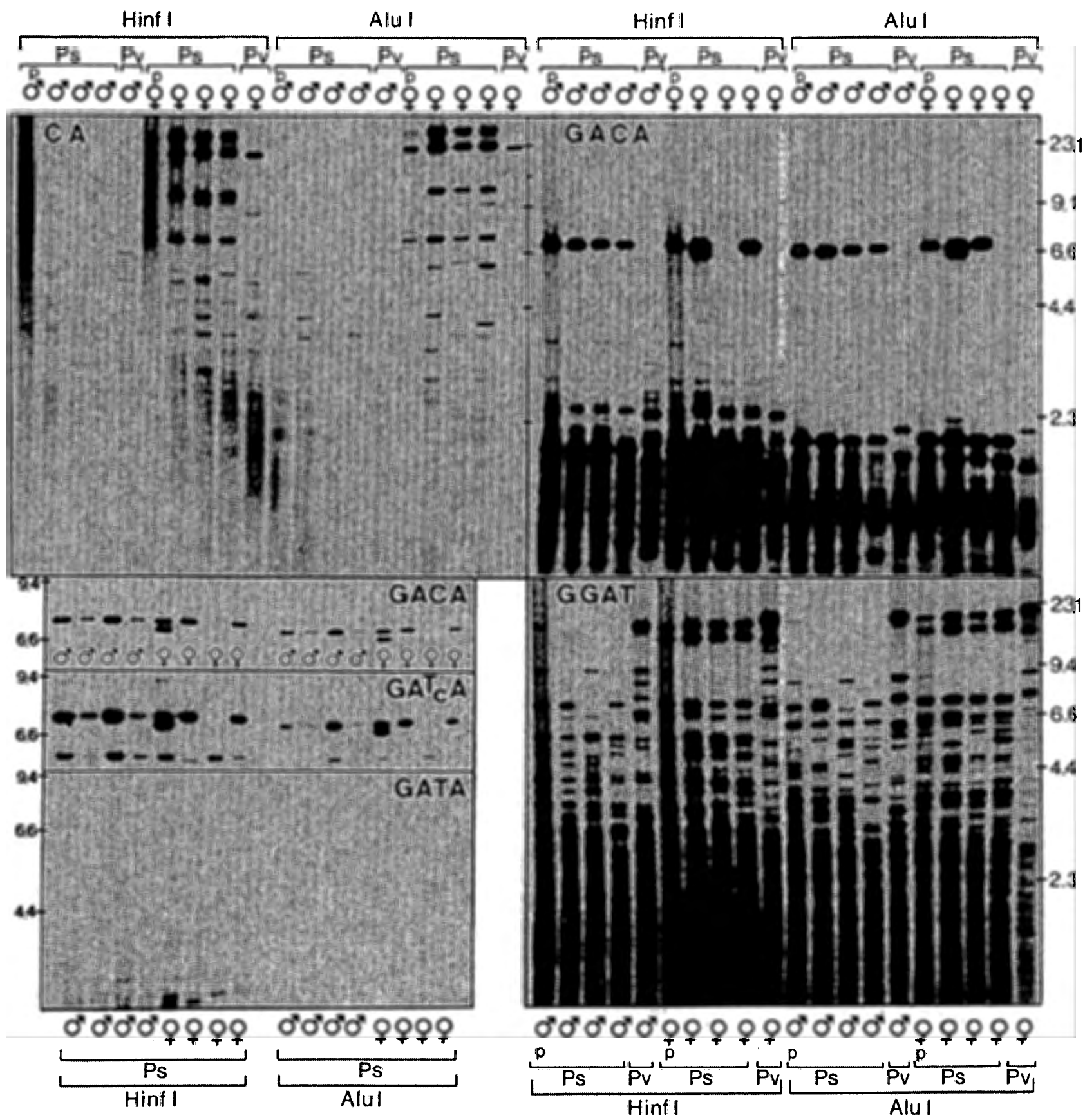

Fig. 2. In-gel hybridization of genomic DNA from Poecilia sphenops $(P s)$ and $P$. velifera $(P v)$ using the oligonucleotides $(C A)_{8}$, $(G A C A)_{4}$ and $(G G A T)_{4}$ as probes. At the bottom left is shown a section of a second gel containing $P$. sphenops DNA samples after hybridization with $(G A C A)_{4},(G A T A)_{3},(G A C A)_{2}$ and $(G A T A)_{4}$. The restriction enzymes HinfI and AluI both produce very similar banding patterns with all three oligonucleotide probes. In separate pools $(p)$ of DNA samples from $P$. sphenops males and females uncharacteristic smear signals appeared throughout

the respective lanes. Note the different patterns between males and females. The hybridizations shown at the bottom left were conducted to separate physically the two $7.5 \mathrm{~kb}$ fragments in DNA of one $P$. sphenops female and to investigate the effects of different compositions of $(\text { gata })_{\mathrm{n}} /(\mathrm{gaca})_{\mathrm{m}}$ probes. The polymorphic $(G A C A)_{4}$ bands at about $7.5 \mathrm{~kb}$ do not harbour significant amounts of pure $(G A T A)_{4}$ simple repeat units. Length markers are indicated in kilobases 
nent sex-specific hybridization in the high molecular weight range in females of $P$. sphenops when the genomic DNA was hybridized with the $(\mathrm{GGAT})_{4}$ and $(\mathrm{GT})_{8} /$ $(\mathrm{CA})_{8}$ probes. This clearly illustrates female heterogamety in $P$. sphenops and it predicts the presence of a $\mathrm{W}$ chromosome (Figs. 1, 2). The specific (ggat) n $_{\mathrm{n}}$ signal in females is confined to the $23 \mathrm{~kb}$ region while the dimeric repeat $(\mathrm{GT})_{8} /(\mathrm{CA})_{8}$ displays multiple bands ranging from $7 \mathrm{~kb}$ to extremely high molecular weights (Figs. 1, 2). On the other hand in $P$. velifera two less prominent but consistent sex-specific signals were noted with $(\mathrm{CA})_{8}$ in females only. Thus the $\mathrm{W}$ chromosome of $P$. velifera may not have attained the same degree of sequence diversification from the $Z$ as observed in the case of $P$. sphenops or as the Y chromosome in $P$. reticulata from the $\mathrm{X}$.

In $X$. maculatus examples of male and female heterogamety with three types of sex chromosomes are known to exist in one and the same population. In the primitive form of chromosomal sex determination sex chromosomes differ from their homologues probably only in a limited number of gene loci. The application of simple repeat probes to the $X$. maculatus model system was based on the idea of allocating certain specific bands to $\mathrm{Y}, \mathrm{W}$ or $\mathrm{X}$ chromosomes. A series of hybridizations with various simple repeats $\left[(\mathrm{GT})_{8} /(\mathrm{CA})_{8},(\mathrm{CAC})_{5}\right.$, $\left.(\mathrm{GGAT})_{4},(\mathrm{GACA})_{4}\right]$ failed to assign any sex-specific band to any of these chromosomes (Fig. 3).
Upon digesting genomic DNA with a panel of restriction enzymes, fish from the Rio Papaloapan population of $X$. maculatus carrying a definite $\mathrm{Y}$ chromosome (marked by the Sp colour gene) exhibited an intense smear signal in males with (GATA) 4 (see Fig. 4 with three enzymes). The smear could be due to the occurrence of many restriction sites spaced at various distances on different $\mathrm{Y}$ chromosomal DNA fragments. More likely, however, very long, native DNA fragments harbour no restriction enzyme recognition sites but are just randomly broken due to the DNA preparation method. Their separation results in the smear signal. Interestingly the $\mathrm{Y}$ chromosomal polymorphism in $X$. maculatus which is phenotypically represented by different colour genes and P alleles (onset of sexual maturation; Kallman 1984) is also evident at the molecular level owing to the simple repeats. While the smear signal was readily detected in the presence of the Rio Papaloapan $Y^{\text {Sp }}$ chromosome, no such hybridization could be assigned to the Rio Jamapa $\mathrm{Y}^{\mathrm{Sp}}$ chromosome (data not shown).

A similar situation became evident when two different populations of $X$. helleri were compared (Fig. 5). The population from Laguna Catemaco differs from that of Rio Lancetilla with respect to the smeared signal in males only. Even after prolonged exposure the same pattern could not be obtained in females. Furthermore the typical smear due to the particular organization of (ga-

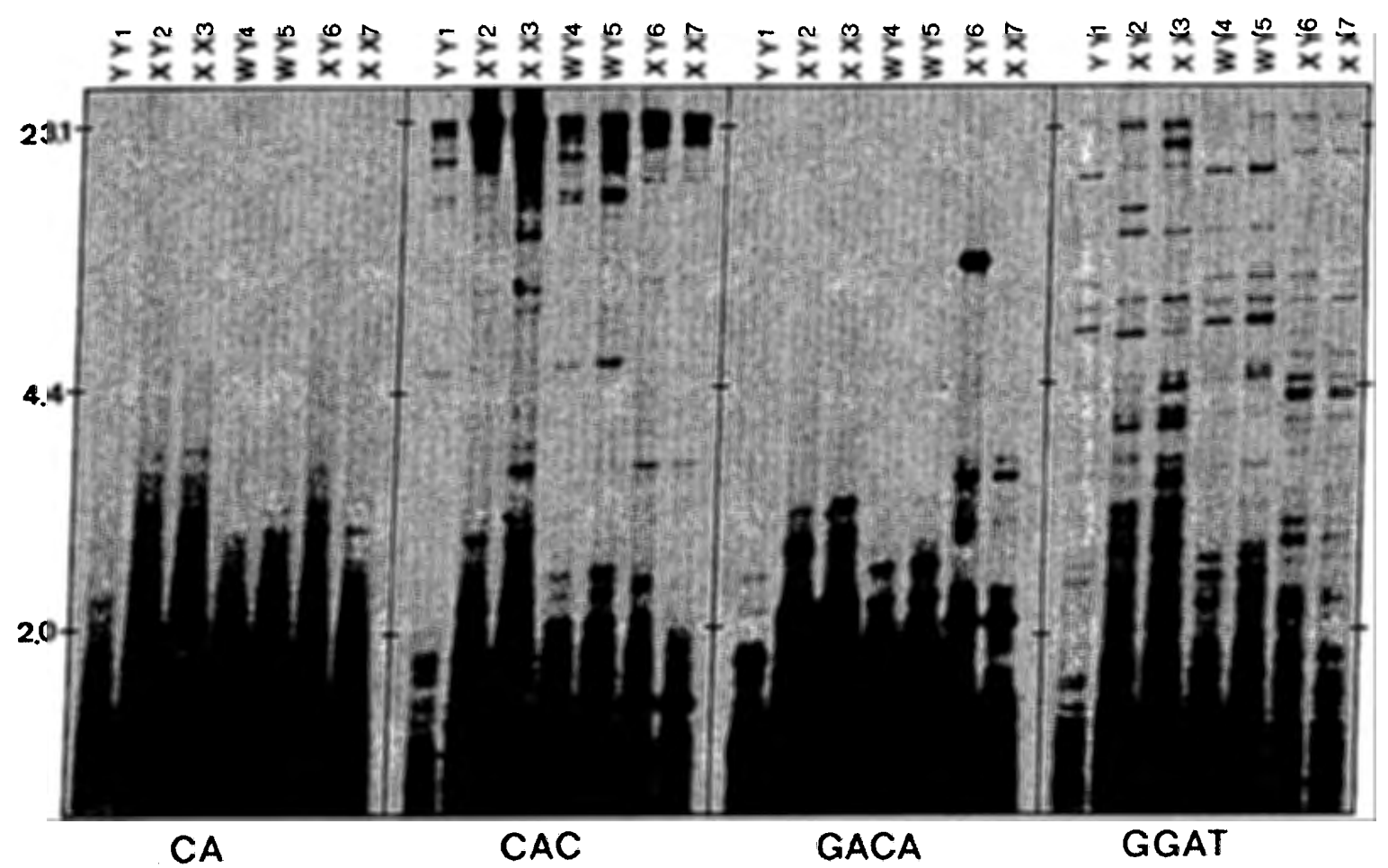

Fig. 3. In-gel hybridization of different Xiphophorus maculatus DNA samples to the oligonucleotide probes $(C A)_{8},(C A C)_{5}$, $(G A C A)_{4}$ and $(G G A T)_{5}$. The specimens included $Y Y$ and $X Y$ males, $X X$ females and $W Y$ females (Rio Coatzecoalcos) as well as $X Y$ males and $X X$ females (Rio Papaloapan): (1) male, $Y^{\text {sp9 }} / Y^{\text {sp9 }} ;(2)$ male, $\mathrm{X}^{+} / \mathrm{Y}^{\mathrm{Sr}}$; (3) female, $\mathrm{X}^{\mathrm{Dr}} / \mathrm{X}^{\mathrm{Dr}} ;$ (4) female, $\mathrm{W} / \mathrm{Y}^{+} ;(5)$ female

$\mathrm{W} / \mathrm{Y}^{+} ;($() $)$male, $\mathrm{X}^{+} / \mathrm{Y}^{\mathrm{N} 2} ;(7)$ female $\mathrm{X}^{+} / \mathrm{X}^{+}$. DNA (6 $\left.\mu \mathrm{g}\right)$ of each individual was digested with the restriction enzyme HinfI. No sex chromosome specific hybridization patterns were revealed with the probes representing simple repeat motifs. Differences in the banding patterns are mostly due to autosomal polymorphisms. Size markers are indicated on the left in kilobases 


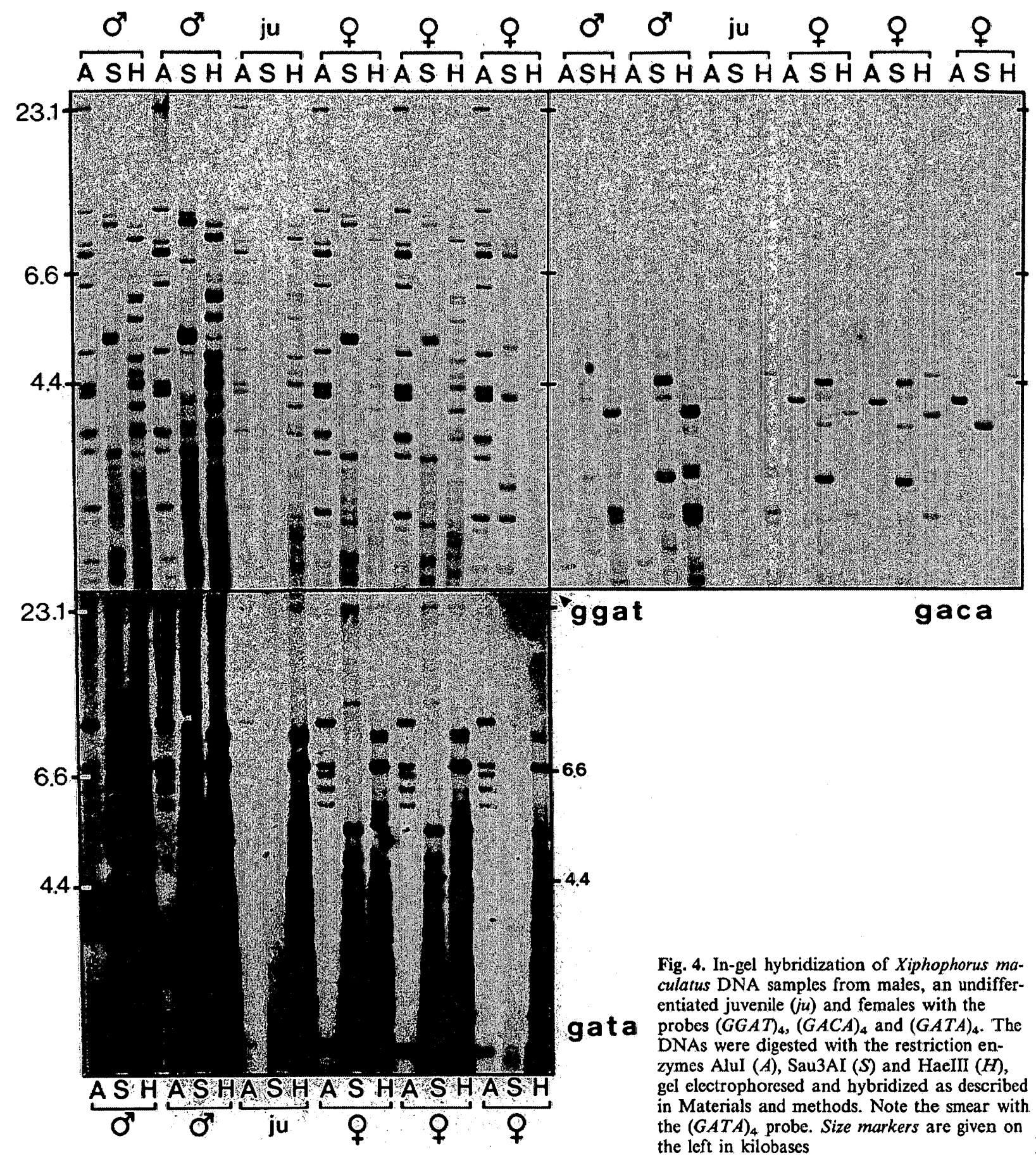

ta) ${ }_{n}$ sequences was confirmed by hybridizing the same gel with related simple repeat probes where this characteristic smear was not seen. In contrast to the situation in $X$. maculatus where (gaca) ${ }_{\mathrm{n}}$ sequences are poorly represented, in the $X$. helleri population a smear was noted in males above the $23 \mathrm{~kb}$ range. In addition a high molecular weight band characteristic of this population (Laguna Catemaco) appeared in both sexes (Fig. 5). On the other hand, in the population from Rio Lancetilla where sex is determined polygenically (Peters 1964), no sexspecific hybridization to any of the simple repeats was

evident. Thus in comparison with the guppy and other Poecilia fish, an entirely different form of Y chromosome organization with respect to simple repetitive sequences could be revealed in populations of Xiphophorus.

Cytogenetic evidence for sex chromosomes in poeciliid fishes

C-banding conducted on chromosomes from numerous specimens of $P$. sphenops revealed a distinct heteromor- 


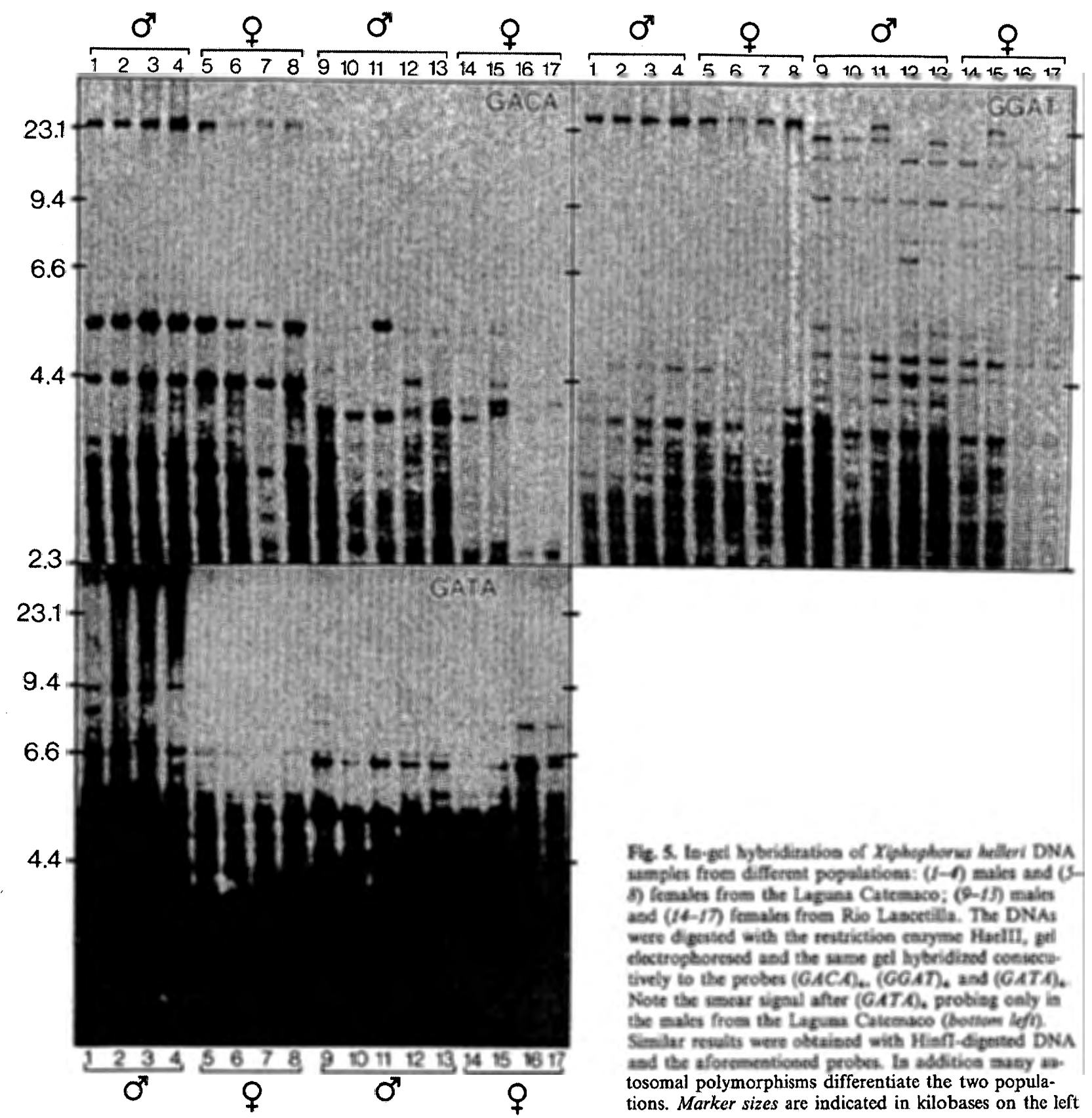

phism between the homologous No. 1 chromosomes in females (Haaf and Schmid 1984). Only one homologue has intensely stained telomeric heterochromatin. Such a C-band difference leads to the conclusion that these are sex-specific chromosomes of the $\mathrm{ZW}$ o/ZZ ot type. In the $\mathrm{C}$-banded preparations the only visible difference between the $\mathrm{Z}$ and $\mathrm{W}$ chromosomes is the telomeric $\mathrm{W}$ heterochromatin. A similar slight difference in the Cbanding patterns has been observed between the telomeres of the homologous No. 1 chromosomes in the male guppy (Nanda et al. 1990). In one of the homologues $(Y)$ there is always distinctly more telomeric heterochromatin than in the other $(X)$. The size of the $Y$ specific heterochromatin shows interindividual variabili- ty. Hybridization of (GACA $)_{4}$ to the chromosomes displays the characteristic peroxidase reaction at the telomeric end of only one of the No. 1 homologues in males (Nanda et al. 1990). Thus the male-specific hybridization pattern with the (GACA) 4 probe is due to the accumulation of simple repeats on the telomeric heterochromatin of the $\mathrm{Y}$ chromosome. In contrast to the aforementioned situations, in $P$. velifera a similar heteromorphism has not been observed indicating that the $\mathrm{Z}$ and $\mathrm{W}$ chromosomes are still structurally equal. Furthermore C-banding reveals no consistent differences between any of the homologous chromosome pairs in $X$. maculatus (Rio Papaloapan population). Only in fish from the Laguna $\mathrm{Ca}$ temaco population of $X$. helleri, where male specific hy- 
bridization was observed with $(\mathrm{GATA})_{4}$, was a very small difference observed between the telomeres of the No. 6 chromosomes in the males analysed. However, this evidence for the beginning of heterochromatization of the $\mathrm{Y}$ chromosome in $X$. helleri must be confirmed in more individuals.

\section{Discussion}

Several vertebrate classes including fish, amphibians and reptiles harbour species with sex chromosomes in an early stage of differentiation (Bull 1983). Morphologically differentiated sex chromosomes, a characteristic of higher vertebrates, are believed to have evolved from identical homologues (Ohno 1967; Jablonka and Lamb 1990; Charlesworth 1991). Comparative studies from different reptiles have been interpreted as indicating that (gata) (gaca $_{m}$ sequences have been important in sex chromosome evolution. In many animals these sequences hybridize to the sex chromosomes carrying the largest amount of heterochromatin (Singh et al. 1976; Jones 1983). Here experimental evidence is presented that various simple repeats are implicated in the early stages of sex chromosome differentiation. We detected a $\mathrm{Y}$ chromosome in $P$. reticulata with the $(\mathrm{GATA})_{4}$ and $(\mathrm{GACA})_{4}$ probes. The same simple sequence failed to reveal sex-specific distinct bands in all populations and species of Xiphophorus investigated. Even in the population where (gata $)_{n} /(\text { gaca })_{m}$ abundance is evident, a completely different pattern of hybridization was obtained. This phenomenon together with that from the guppy perhaps entail different stages in the incipient process of $Y$ chromosome specialization. The lack of sex-associated differences in (gata $)_{n} /(\text { gaca })_{m}$ sequence organization in $P$. sphenops and $P$. velifera may have the following explanation: (1) accumulation of these sequences is not an important step in sex chromosome differentiation. (2) Since there are only small amounts of heterochromatin on the sex chromosomes ( $P$. velifera, as evidenced by C-banding), there may be an insufficient amount of the simple sequences present on the sex chromosome to be detected. However, this explanation does not seem to be correct as sex-specific hybridization signals are found with other simple repeats. Moreover our data suggest that (gata) $/$ (gaca) $m$ sequences are not the exclusive sequences involved in sex chromosome evolution. Supporting evidence for this has been found in the rainbow trout ( $\mathrm{Sal}$ mo gairdneri; Lloyd et al. 1989) and Leporinus obtusidens of the family Anostomidae (our own unpublished data), where sex chromosomes could be identified by cytological staining but sex-specific differences could not be observed using cloned $\mathrm{Bkm}$ sequences or oligonucleotides as hybridization probes. Furthermore other recent observations from mammalian systems question the previous speculation of the general relevance of (gata) $n$ / (gaca $_{m}$ in sex chromosome evolution (Miklos et al. 1989). In addition distinct sex-specific hybridization with $(\mathrm{CA})_{8}$ and $(\mathrm{GGAT})_{4}$ reveals that several different simple repeat elements may have accumulated independently on the sex chromosomes. This phenomenon is not exclusive to poeciliid fishes but has also been observed in rodents of the genus Mus. In these, typical Y-specific hybridization with (gata $)_{\mathrm{n}} /(\text { gaca })_{\mathrm{m}}$ simple repeats is highly variable (Epplen et al. 1988). Therefore association of other types of simple repeats has been suggested to explain male specific "satellite bands" observed on ethidium bromide stained gels (Platt and Dewey 1987).

There is as yet no adequate explanation for the mode of simple repeat accumulation in the eukaryote genome (Epplen 1988). It is envisaged that simple repeats are randomly generated on all chromosomes at a high frequency due to anomalous replication from a pool of low molecular weight forms (Tautz and Renz 1984). It is likely that owing to point mutations, slipped strand mispairing and crossover events during meiosis these sequences may be reduced in the genome while sequences on the $\mathrm{Y}$ chromosome will be preserved for longer time intervals as a result of its perpetually haploid state: therefore the three above mentioned mechanisms may still be in operation on poeciliid sex chromosomes with their high overall homology except for nascent differentiation.

Our observations illustrate various stages of sex chromosome differentiation specific for each poeciliid species or population: (1) in the guppy, where the genetic basis of heterogamety has already been established, the nature of the $\mathrm{Y}$ chromosome can be confirmed by molecular and cytogenetic means. In some inbred lines of the guppy male specific hybridization in the high molecular weight region is absent, which may be related to the $\mathrm{Y}$ chromosome polymorphism in natural populations (Nanda et al. 1990). (2) In those systems where genetic experiments on the sex chromosome mechanisms have not been reported, the sex chromosome status could be inferred by specific hybridization patterns $(P$. velifera and $P$. sphenops). (3) In Xiphophorus the sex determination polymorphism has been attributed to the varying combinations of different sex chromosomes. The present study demonstrates evidence for the occurrence of a $\mathrm{Y}$ chromosome on the basis of hybridization patterns. Therefore, the lack of sex-specific hybridization in many populations may point to different stages of sex chromosome evolution in Xiphophorus.

$X$. helleri is well known for its polygenic mode of sex determination where many male or female determining genes are distributed on several chromosomes (Orzack et al. 1980). The determination of sex depends on the cumulative expression of any one set of these genes. In the phylogeny of sex chromosomes such a mechanism is considered to be most primitive. Eventually it is replaced by a genic system among fishes (Kirpichnikov 1981). Recent linkage analyses and mathematical models suggest that such a polygenic system is unstable and it has been shown to acquire "sexually antagonistic" genes (Rice 1986). The sex-specific signal with (GATA) in the Laguna Catemaco population of $X$. helleri could be explained by a similar mechanism. We present here for the first time evidence that in the swordtail a heterogametic system is present besides the commonly known polygenic mode. This is in perfect confirmation of genet- 
ic experiments and sex ratios on different $X$. helleri populations (Kallman 1984).

Based on studies in snakes Ohno (1967) stressed pericentric inversion as the probable mechanism of generation of heteromorphic sex chromosomes from a homomorphic sex element. This suggestion may be valid for those systems where size differences between the sex chromosomes are established. Poecilia fishes and many amphibians on the contrary do not display apparent morphological differences between the sex chromosomes. Therefore other mechanisms must have been operating in these systems. One possible mechanism is based on cytological heteromorphism where one homologue has dramatically different $\mathrm{C}$-band characteristics compared with its partner in one sex but never in the other (Schmid 1980; King 1980). While the cytological evidence for the incipient $\mathrm{W}$ chromosome in P. sphenops (see Haaf and Schmid 1984) fits directly into this model our observations on the guppy as well as on $P$. velifera may imply that the initial heterochromatization in primordial sex chromosomes is not the result of a single structural event. Instead several different processes may be involved.

The mechanism of sexual differentiation and development of heterogamety was initially investigated via genetic experiments in several teleosts. This cumbersome method was later replaced by application of modern cytogenetic techniques which to some extent revealed heteromorphic sex chromosomes in certain species (Thorgaard 1977; Galetti and Foresti 1986). Other non-cytogenetic parameters such as screening for $\mathrm{H}-\mathrm{Y}$ antigen were applied to different poeciliid systems which coincided with the known heterogametic situations (Pechan et al. 1979; Nakamura and Wachtel 1984). Owing to methodological difficulties this could not be applied extensively to other poeciliid fishes where genetic heterogamety had not been demonstrated. Recently the so-called ZFY sequence, a "zinc finger" protein encoded by the human Y (Page et al. 1987), has been postulated to be associated with the sex chromosomes of many diversified vertebrates. This view, however, remains controversial because of reports on marsupials (Sinclair et al. 1988) and reptiles (Bull et al. 1988). In addition ZFY sequences are present but also not informative with respect to the sex chromosomes in Xiphophorus (S.M. Robertson and $M$. Schartl, unpublished data) and in the guppy and $P$. sphenops (I. Nanda et al., unpublished data). Hence the present approach using simple repeats proves to be superior for the unravelling of the heterogametic status in lower vertebrates. It is also useful for revealing extensive polymorphism for individualization purposes. For example the (GGAT) ${ }_{4}$ sequence reveals numerous polymorphic bands in each poeciliid fish studied and thus provides highly informative DNA fingerprints.

Acknowledgements. The excellent technical assistance of B. Wilde and S. Hölter (to M.S.) is gratefully acknowledged as well as the supply of biotinylated oligonucleotides by $\mathrm{H}$. Zischler. This work has been supported by the Deutsche Forschungsgemeinschaft (Ep 7/6-1. Scha 408/2-3, and Schm 484/4-2). The oligonucleotide probes are subject to patent applications. Commercial enquiries should be directed to Fresenius AG, Oberursel, FRG.

\section{References}

Aida T (1921) On the inheritance of color in a fresh water fish, Apocheilus latipes, with special reference to sex-linked inheritance. Genetics 6:554-573

Beçak W (1983) Evolution and differentiation of sex chromosomes in lower vertebrates. In: Müller U, Franke WW (eds) Mechanism of gonadal differentiation in vertebrates. Differentiation [Suppl] 23:S3-12

Blin N, Stafford DW (1976) A general method for isolation of high molecular weight DNA from eukaryotes. Nucleic Acids Res 3:2303-2308

Bull JJ (1983) Evolution of sex determining mechanisms. Benjamin/ Cumming, Menlo Park, Calif

Bull JJ, Hillis DM, O'Steen S (1988) Mammalian ZFY sequences exist in reptiles regardless of sex-determining mechanism. Science 242:567-569

Charlesworth B (1991) The evolution of sex chromosomes. Science 251:1030-1033

Ebeling AW, Chen TR (1970) Heterogamety in teleostean fishes. Trans Am Fish 99:131-138

Epplen JT (1988) On simple repetitive GATA/GACA sequences in animal genomes: a critical reappraisal. J Hered 79:409-417

Epplen JT, McCarrey JR, Sutou S, Ohno S (1982) Base sequence of a cloned snake W-chromosome DNA fragment and identification of a male-specific putative mRNA in the mouse. Proc Natl Acad Sci USA 79:3798-3802

Epplen JT, Studer R, McLaren A (1988) Heterogeneity in the Sxr (sex-reversal) locus of the mouse as revealed by synthetic GATA/GACA probes. Genet Res 51:239-246

Foerster W, Anders F (1977) Zytogenetischer Vergleich der Karyotypen verschiedener Rassen und Arten lebendgebärender Zahnkarpfen der Gattung Xiphophorus. Zool Anzeiger 198:167-177

Galetti PM, Foresti F (1986) Evolution of the ZZ/ZW system in Leporinus (Pisces, Anostomidae): role of constitutive heterochromatin. Cytogenet Cell Genet 43:43-48

Gold JR (1979) Cytogenetics. In: Hoar WS, Randall DJ, Brett JR (eds) Fish physiology, vol 8. Academic Press, New York, pp 353-405

Gordon M (1947) Genetics of Platypoecilus maculatus. IV. The sex-determining mechanism in two wild populations of the mexican platy fish. Genetics 32:8-17

Gordon M (1951) Genetics of Platypoecilus maculatus. V. Heterogametic sex-determining mechanism in females of a domesticated stock originally from British Honduras. Zoologica 36:127134

Haaf T, Schmid M (1984) An early stage of ZW/ZZ sex chromosome differentiation in Poecilia sphenops var. melanistica (Poeciliidae, Cyprinodontiformes). Chromosoma 89:37-41

Jablonka E, Lamb MJ (1990) The evolution of heteromorphic sex chromosomes. Biol Rev 65:249-276

Jones KW (1983) Evolutionary conservation of sex specific sequences. Differentiation [Suppl] 23:S56-59

Jones KW, Singh L (1985) Snakes and the evolution of sex chromosomes. Trends Genet $1: 55-61$

Kallman KD (1973) The sex-determining mechanism of the platyfish, Xiphophorus maculatus. In: Schröder JH (ed) Genetics and mutagenesis of fish. Springer, Berlin Heidelberg New York, pp 19-28

Kallman KD (1984) A new look at sex determination in poeciliid fishes. In: Turner BJ (ed) Evolutionary genetics of fishes. Plenum Press, New York, pp 95-171

King M (1980) C-banding studies on Australian hylid frogs: secondary constriction structure and the concept of euchromatin transformation. Chromosoma 80:191-217

Kirpichnikov VS (1981) Genetic bases of fish selection. Springer, Berlin Heidelberg New York

Lloyd MA, Fields MJ, Thorgaard GH (1989) Bkm minisatellite sequences are not sex associated but reveal DNA fingerprint polymorphism in rainbow trout. Genome 32:865-868

Miklos GL, Matthaei KI, Reed KC (1989) Occurrence of the (GA- 
TA) $n$ sequences in vertebrate and invertebrate genomes. Chromosoma 98:194-200

Nakamura D, Wachtel SS (1984) H-Y antigen and the evolution of heterogamety. J Hered 75:353-358

Nanda I, Feichtinger W, Schmid M, Schröder JH, Zischler H, Epplen JT (1990) Simple repetitive sequences are associated with the differentiation of the sex chromosomes in the guppy fish. J Mol Evol 30:456-462

Ohno S (1967) Sex chromosomes and sex-linked genes. Springer, Berlin Heidelberg New York

Orzack SH, Sohn JJ, Kallman KD, Levin SA, Johnston R (1980) Maintenance of the three sex chromosome polymorphism in the platyfish, Xiphophorus maculatus. Evolution 34:663-672

Page DC, Mosher R, Simpson EM, Fisher EMC, Mardon G, Pollack J, McGillivray B, de la Chapelle A, Brown LG (1987) The sex determining region of the human $\mathrm{Y}$ chromosome encodes a finger protein. Cell 51:1091-1104

Pechan P, Wachtel SS, Reinboth R (1979) H-Y antigen in the teleost. Differentiation 14:189-192

Peters G (1964) Vergleichende Untersuchungen an drei Subspecies von Xiphophorus helleri Heckel (Pisces). Z Zool Syst Evolutionsforschung 2:185-271

Platt THK, Dewey MJ (1987) Multiple forms of male-specific simple repetitive sequences in the genus Mus. J Mol Evol 25:201206

Price DJ (1984) Genetics of sex determination in fishes - a brief review. In: Fish reproduction. Academic Press, New York, pp 77-89

Rice WR (1986) On the stability of polygenic sex determination: the effect of sex-specific selection. Evolution 40:633-639
Schäfer R, Zischler H, Birsner U, Becker A, Epplen JT (1988) Optimized oligonucleotide probes for DNA fingerprinting. Electrophoresis 9:369-374

Schmid M (1980) Chromosome banding in Amphibia. V. Highly differentiated $\mathrm{ZW} / \mathrm{ZZ}$ sex chromosomes and exceptional genome size in Pyxicephalus adspersus (Anura, Ranidae). Chromosoma 80:69-96

Sinclair AH, Foster JW, Spencer JA, Page DC, Palmer M, Goodfellow PN, Graves JAM (1988) Sequences homologous to ZFY, a candidate human sex-determining gene, are autosomal in marsupials. Nature 336:780-783

Singh L, Purdom IF, Jones KW (1976) Satellite DNA and evolution of sex chromosomes. Chromosoma 59:43-62

Singh L, Purdom IF, Jones KW (1981) Conserved sex chromosome-associated nucleotide sequences in eukaryotes. Cold Spring Harbor Symp Quant Biol 45:805-814

Singh L, Phillips C, Jones KW (1984) The conserved nucleotide sequences of $\mathrm{Bkm}$, which define Sxr in the mouse, are transcribed. Cell 36:111-120

Tautz D, Renz M (1984) Simple sequences are ubiquitous components of eukaryotic genomes. Nucleic Acids Res 12:4127-4138

Thorgaard GH (1977) Heteromorohic sex chromosomes in male rainbow trout. Science 196:900-902

Winge O (1922) One-sided masculine and sex-linked inheritance in Lebistes reticulatus. J Genet 12:145-162

Winge O, Ditlevsen E (1947) Color inheritance and sex determination in Lebistes. Heredity 1:65-83

Yamamoto T (1961) Progenies of induced sex-reversal females mated with induced sex-reversal males in the medaka, Oryzias latipes. J Exp Zool 146:133-154 